\title{
Qingfei Tongluo formula attenuated pulmonary inflammation and embolism in mycoplasma pneumonia mice
}

\section{Yong-hong Jiang ( $\sim$ jyh203225@126.com )}

Pediatric Department of Longhua Hospital https://orcid.org/0000-0003-1238-2723

\section{Zhen xiao}

Department of pediatric,Longhua Hospital affiliated to Shanghai University of TCM

\section{Zhi-Yan Jiang}

Department of pediatric,Longhua Hospital affiliated to Shanghai University ofTCM

\section{Xiao-Yang Zhao}

Department of pediatric,Longhua Hospital affiliated to Shanghai University of TCM

Jia-jia Lv

Department of pediatric,Longhua Hospital affiliated to Shanghai University of TCM

Qian Li

Longhua Hospital affiliated to Shanghai University of TCM

\section{Research}

Keywords: pneumonia, mouse, embolism, TLR4, NF-KB

Posted Date: July 7th, 2020

DOl: https://doi.org/10.21203/rs.3.rs-35944/v1

License: (9) (i) This work is licensed under a Creative Commons Attribution 4.0 International License. Read Full License 


\section{Abstract \\ Background}

Qingfei Tongluo formular (QT) is a homemade agent for the Mycoplasma pneumoniae pneumonia (MPP) treatment developed by pediatrics of Shanghai Longhua hospital, which combining with AZM(azithromycin) has better clinical curative effect. This study aims at exploring the chemical components and clarifying the possible mechanism involved in.

\section{Methods}

LC-MS was used for chemical analysis. The mycoplasma pneumoniae infected mice were treated with AZM and QT (46.25 and $92.5 \mathrm{mg} / \mathrm{g}$ ) for 3 days. Polymorphonuclear neutrophils (PMNs) and monocytes in bronchoalveolar lavage fluid (BALF) were measured by haemacytometer. IL-6, IL-10, IL-1 $\beta$ and IL-13 in BALF were identified by ELISA assay. HE staining was employed for histological examination. TLR4, COX2 and NF-KB expressions were assessed by western blot.Student's $t$ test was used to compared the differences between two groups, while one-way analysis of variance was used when more than two groups were compared. $P<0.05$ was taken as statistical significance.

\section{Results}

10 compounds were identified in QT. After QT treatment, PMNs and monocytes in BALF were reduced and release of inflammatory cytokines was also mediated. HE staining showed that QT effectively arbitrated the inflammation and embolism in lung tissue. QT also blocked the TLR4-NF-KB-COX-2 signaling.

\section{Conclusions}

QT showed favorable effect in MPP treatment by diminishing the inflammation symptoms and regulating the TLR4-NF-KB-COX-2 signaling, which could act as a new agent for MPP therapy.

\section{Background}

Mycoplasma pneumoniae (MP) is one of the main pathogens of community-acquired pneumonia in children, and the incidence of mycoplasma pneumoniae pneumoniae (MPP) increased gradually ${ }^{[1]}$. Resent years, MP gradually tends to be resistant to antibiotics, which leads to hard to cure and easy to recur and MPP increased year by year. Furthermore, MPP tends to cause asthma by affecting the respiratory epithelium and also can result in pulmonary fibrosis ${ }^{[2]}$. Therefore, it is urgent to explore effective prevention and treatment for pediatric MPP from perspective of traditional Chinese medicine (TCM). 
Qingfei Tongluo formular (QT) is a homemade agent for the MPP treatment developed by pediatrics of Shanghai Longhua hospital, which has better clinical curative effect. Qingfei Tongluo formular contains cortex mori from Morus alba L. (9 g), cortex lycii Lycium chinense Mill. (9 g), peach kernel from Prunus persica L. (9 g), aidicha from Ardisia japonica (Thumb.) Blume $(9 \mathrm{~g})$, lumbricus from Pheretimaas pergilum (E Perrier) (9 g), almond from Amygdalus communis Vas (9 g), perillaseed from Perilla frutescens (L.) Britt. (9 g), semen lepidii from Heleocharis dulcis (Burm. f.) Trin. (9 g) and liquorice from Glycyrrhiza uralensis Fisch. $(3 \mathrm{~g})^{[3]}$. From our previous studies, we found that the clinical cure rate was $94.67 \%$ by QT combining with azithromycin treatment ${ }^{[4]}$. Current years, TCM research towards MPP mainly focuses on the introduction of clinical experience, while studies based on animal models and the mechanisms involved in is imperative to carry out.

In this study, a BALB/c mouse model of MP infection was established and employed for studying the curative effect of QT on the MPP, the chemical constituents of QT were also identified.

\section{Meterials And Methods}

\subsection{Preparation of MP extracts}

MP, ATCC15531 strain (American Type Culture Collection, Rockville, MD) was cultured in modified Hayflick medium (GZBIOTEST Co., Ltd, Guangdong, China) containing PPLO broth, horse serum, 25\% yeast extract, which was added with penicillin $\mathrm{G}(1000 \mathrm{u} / \mathrm{ml})$, thallium acetate $(0.025 \%)$, glucose $(0.5 \%)$ and phenol red $(0.002 \%), \mathrm{pH}=7.6$. MP was cultured at $37^{\circ} \mathrm{C}$ under $5 \% \mathrm{CO}_{2}$ for 7 days.

\subsection{Qingfei Tongluo formular water extracts}

Qingfei Tongluo formular and was purchased from Longhua hospital affiliated to Shanghai University of traditional Chinese medicine. All medical materials were decocted by boiling in distilled water to obtain QT water extracts, and water extracts was adjusted to $3.7 \mathrm{~g} / \mathrm{ml}$.

\subsection{Animals}

BALB/c mice (3-week-old, $15 \pm 1 \mathrm{~g}$ ) were purchased from Shanghai sippr bk laboratory animals Co. Ltd. (Shanghai, China) and fed with feedstuff and water in a specific pathogen free (SPF) environment. All mice were with ether anesthesia and divided into five groups as control, model, AZM, QT $(46.25 \mathrm{mg} / \mathrm{g})$ and QT $(92.5 \mathrm{mg} / \mathrm{g})$ randomly. Mice in control group were treated with $100 \mu \mathrm{l}$ normal saline by nasal drip

[5]. Model, AZM, QT $(46.25 \mathrm{mg} / \mathrm{g})$ and QT $(92.5 \mathrm{mg} / \mathrm{g})$ groups were given with nasal drops containing $100 \mu \mathrm{MPFH}\left(1 \times 10^{7} \mathrm{ccu} / \mathrm{ml}\right)$ for 2 days. Control and model groups were given by gavage once a day with $0.25 \mathrm{ml} / 20 \mathrm{~g}$ normal saline. AZM, QT $(46.25 \mathrm{mg} / \mathrm{g})$ and QT $(92.5 \mathrm{mg} / \mathrm{g})$ groups were given by gavage with $46.25 \mathrm{mg} / \mathrm{g}$ AZM (Pfizer, New York, USA, 1164096), $46.25 \mathrm{mg} / \mathrm{g}$ QT water extracts and $92.5 \mathrm{mg} / \mathrm{g}$ QT water extracts 3 days, respectively. Ethical approval for the study was provided by the independent ethics committee, Shanghai University of traditional Chinese medicine.

\subsection{LC-MS analysis of QT}


An Agilent 1100 HPLC system, equipped with a quaternary pump, an autosampler, a degasser, an automatic thermostatic column compartment, a DAD and an LC/MSD Trap XCT ESI mass spectrometer (Agilent Technologies, MA, USA), was used for the separation. The separation was performed on a GS120-5-C18-BIO chromatographic column $(5 \mu \mathrm{m}, 250 \cdot 4.6 \mathrm{~mm}$ i.d. $)$ with the column temperature set at $35^{\circ} \mathrm{C}$. A linear gradient elution of $A(0.1 \%$ formic acid water) and $B$ (acetonitrile) was used with the

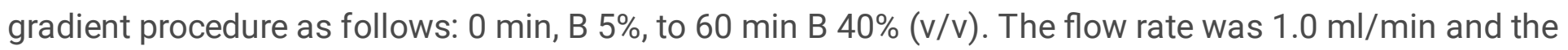
injection volume was $10 \mu \mathrm{L}$. DAD was on and the target wavelength was simultaneously set at $210 \mathrm{~nm}$. The split ratio to the mass spectrometer was 1:3. The acquisition parameters for negative ion mode were: collision gas, ultra high-purity helium (He), nebulizer gas (N2), 35 psi, drying gas (N2), $10 \mathrm{l} / \mathrm{min}$, drying temperature, $350{ }^{\circ} \mathrm{C}, \mathrm{HV}, 3500 \mathrm{~V}$, mass scan range, $\mathrm{m} / \mathrm{z} 100-2200$, target mass, $500 \mathrm{~m} / \mathrm{z}$, compound stability, $100 \%$, trap drive level, $100 \%$. All the data were analysis by Chemstation software.

\subsection{Inflammatory cells}

Leukocyte recruitment to alveoli was determined in the broncho alveolar lavage fluid (BALF). Briefly, animals were sacrificed under ether anesthesia and trachea was exposed and intubated with a catheter, and then repeated $1 \mathrm{ml}$ injections of PBS were made until a total of $3 \mathrm{ml}$ of BALF was recovered. BALF was centrifuged at $3,400 \times \mathrm{g}$ for $10 \mathrm{~min}$, and supernatant was frozen at $-80^{\circ} \mathrm{C}$ until analysis of inflammatory mediators. Cells in the pellet were resuspended in PBS for quantification of leukocytes with a haemacytometer, and cell populations were enumerated from Diff-Quik Stain kit (Thermo Fisher Scientific Inc.).

\subsection{Histological examination}

Inferior lobe of right lung isolated on the 3th day was fixed with $4 \%$ paraformaldehyde, embedded with paraffin and cut into slices for HE staining. Morphometric analysis was performed by optical microscope (LEICA DMLB, Germany).

\subsection{ELISA}

Cytokine (IL-6, IL-10, TNF- $a$ and IL-13) was measured by ELISA assay. Briefly, lung homogenates were lysed in lysis buffer $\mathrm{pH} 7.4$ which is consisted of $300 \mathrm{mM} \mathrm{NaCl} / \mathrm{L}, 15 \mathrm{mM} \mathrm{TRIS} / \mathrm{L}, 2 \mathrm{mM} \mathrm{MgCl} 2 / \mathrm{L}, 2 \mathrm{mM}$ Triton $\mathrm{X}-100 / \mathrm{L}, 20 \mathrm{ng}$ pepstatin $\mathrm{A} / \mathrm{mL}, 20 \mathrm{ng}$ leupeptin $/ \mathrm{mL}$, and $20 \mathrm{ng}$ aprotinin/mL. Then lung homogenates were centrifuged at $1500 \times \mathrm{g}$ for $15 \mathrm{~min}$ at $4{ }^{\circ} \mathrm{C}$; the supernatant was frozen at $-20^{\circ} \mathrm{C}$, until cytokine measurement by ELISA as per manufacturer's protocol (Ray Biotech).

\subsection{Western blot}

Lung tissues were harvest and washed twice with PBS and lysed in ice-cold radio immunoprecipitation assay buffer (RIPA, Beyotime, Shanghai, China) with freshly added $0.01 \%$ protease inhibitor cocktail (Sigma, St. Louis, MO, USA) and incubated on ice for $30 \mathrm{~min}$. Tissue lysis was centrifuged at 13,000 rpm for 10 min at $4{ }^{\circ} \mathrm{C}$. The supernatant (20-30 $\mu$ g of protein) was run on $10 \%$ SDS-PAGE gel and transferred electrophoretically to a polyvinylidene fluoride membrane (Millipore, Bredford, USA). The blots were blocked with $5 \%$ skim milk, followed by incubation with primary antibodies. Antibodies against COX-2, 
TLR2 and TLR4 were purchased from Abcam. Antibodies against NF-KB, $\beta$-actin and H3 were purchased from Santa. Blots were then incubated with goat anti-mouse secondary antibody (Beyotime, Shanghai, China) or goat anti-rabbit secondary antibody (Beyotime, Shanghai, China) and visualized using enhanced chemiluminescence (ECL, Millipore).

\subsection{Statistical analysis}

The GraphPad Prism 5.0 software system was employed for statistical analysis. Data are expressed as the mean \pm standard error. Student's $t$ test was used to compared the differences between two groups, while one-way analysis of variance was used when more than two groups were compared. $P<0.05$ was taken as statistical significance.

\section{Results}

\subsection{The identification of ten compounds}

The aqueous extract of mixed nine Chinese medicinal materials was measured by high-performance liquid chromatography coupled with electrospray mass spectrometry (HPLC/ESI-MS) in negative-ion mode (Fig. 1a-m). Ten compounds 1-10, with the retention time at $12.0 \mathrm{~min}, 14.0 \mathrm{~min}, 14.7 \mathrm{~min}$, $15.1 \mathrm{~min}, 17.4 \mathrm{~min}, 26.0 \mathrm{~min}, 29.7 \mathrm{~min}, 31.9 \mathrm{~min}, 48.7 \mathrm{~min}$, and $51.8 \mathrm{~min}$, were identified as kukoamine $\mathrm{A}$ (1), bergenin (2), mulberroside A (3), isorhamnetin-3-O- $\beta$-D-glucoside (4), amygdalin (5), liquiritin (6), kaempferol-7-0- $\beta$-D-glucopyranoside (7), rosmarinic acid (8), licoricesaponin G2 (9), and glycyrrhizinic acid (10), on the basis of the observation of the pseudomolecular ion peak at m/z 529.3 [M-H]- (1), m/z 326.9 [M-H]- (2), m/z 567.1 [M-1]- (3), m/z 477.1 [M-1]- (4), m/z 502.1 [M + Cl]- and 913.1 [2M-1]- (5), m/z 417.0 [M-1]- (6), m/z 446.9 [M-1]- (7), m/z 358.9 [M-1]- (8), m/z 837.4 [M-1]- (9), m/z 821.3 [M-1]- (10) in HPLC/ESI-MS chromatogram, in accordance with the molecular weights of ten compounds (kukoamine A, bergenin, mulberroside A, isorhamnetin-3-O- $\beta$-D-glucoside, amygdalin, liquiritin, kaempferol-7-0- $\beta$-Dglucopyranoside, rosmarinic acid, licoricesaponin G2, and glycyrrhizinic acid) (Fig. 2).

\subsection{Estimation of inflammatory cells in BALF}

Leukocyte recruitment to alveoli was determined in the BALF. Compared to the untreated control group, MP-treated group exhibited steady drop in PMN counts in BALF. AZM, QT (46.25 mg/g) and QT $(92.5 \mathrm{mg} / \mathrm{g}$ ) were effective in down regulating PMN counts (Fig. 3A). As for the monocyte recruitment in alveoli (BALF), a significant increase was noted in MP treated mice. A significant reduction in those cell counts was observed after AZM, QT $(46.25 \mathrm{mg} / \mathrm{g})$ and QT $(92.5 \mathrm{mg} / \mathrm{g})$ treatment compared to the model group (Fig. 3B).

\subsection{QT mediated the cytokines in BALF}

Levels of cytokines in lung homogenates were measured. An increase in the levels of cytokines as IL-6, IL13 and TNF-a was seen in the lungs of MP treated mice, and was reduced after AZM, QT $(46.25 \mathrm{mg} / \mathrm{g})$ 
and QT $(92.5 \mathrm{mg} / \mathrm{g})$ treatment (Fig. 4A, C and D). In addition, the lung IL-10 was after MP treatment, when compared to untreated mice. AZM, QT $(46.25 \mathrm{mg} / \mathrm{g})$ and QT $(92.5 \mathrm{mg} / \mathrm{g})$ effectively increased the IL-10 level in BALF (Fig. 4B).

\section{Lung histopathology}

To investigate the histopathological changes underlying MP induced experimental pneumonia in mice lungs and subsequent recovery from this disease state using AZM and QT. Figure 5A shows normal lung histology of mice. The sections of normal lungs shows alveoli is composed of a single layer of squamous epithelium, bronchioles are lined by ciliated columnar epithelium (larger bronchioles) or cuboidal epithelium (smaller bronchioles leading to alveoli). Between the alveoli a thin layer of connective tissue and numerous capillaries also lined with simple squamous epithelium. Figure 5B shows MP infected lung histology of mice. There are congestion and edema of pulmonary interstitial around vessels, pulmonary embolism was observed. In the segmental bronchi, lymphocytes and plasmacytes are infiltrative peripherally. The alveolar walls are thickened and damaged, and a narrowing of the bronchial tubes is seen. Figure $5 \mathrm{C}$ shows lung histology as a result of treatment with AZM. The inflammation was dramatically reduced, and few residual inflammatory cells were observed. The alveolar structure is still maintained, few bronchus is narrowed. Figure 5D shows histological changes in lungs of mice treated with QT $(46.25 \mathrm{mg} / \mathrm{g})$. Inflammation response is reduced. Congestion and edema of pulmonary are interstitial around vessels. In the segmental bronchi, a part of lymphocytes and plasmacytes are infiltrative peripherally. The alveolar walls are thickened, and a narrowing of the bronchial tubes is seen. In Fig. 5 (E), QT at dose of $92.5 \mathrm{mg} / \mathrm{g}$ effectively arbitrates the pulmonary inflammation. Less congestion and edema of pulmonary are interstitial around vessels, and few lymphocytes and plasmacytes are infiltrative peripherally. Pulmonary embolism is disappeared. The alveolar structure is almost perfectively maintained.

Effects of QT on COX-2, TLR4 and NF-KB expression

Expression of COX-2, TLR4 and NF-KB in lung tissue of mice was identified by western blot. As shown in Fig. 6A, B and C, MP notably induced high expression of COX2 and TLR4 in lung tissue compared with the control group. Dramatic falls of COX-2 and TLR4 were observed in AZM, QT (46.25 mg/g) and QT $(92.5 \mathrm{mg} / \mathrm{g})$ groups (Fig. 6A and B). NF-KB expression in cell nucleus was also measured. MP treatment induced an immediate increase of NF-KB expression in lung tissue, and AZM, QT (46.25 mg/g) and QT (92.5 mg/g) effectively reduced the NF-kB expression (Fig. 6C and D).

\section{Discussion}

Pneumonia is identified as a common disease occurred in children, which has been listed as one of the three most serious global pediatric diseases worldwide by the world health organization (WHO $)^{[6-7]} .19 \%$ of children under 5 die of pneumonia from the WHO statistics ${ }^{[8]}$. Pneumonia is an inflammatory condition of the lung affecting primarily the microscopic air sacs known as alveoli. It is usually caused by infection with viruses or bacteria and less commonly other microorganisms, certain drugs and other conditions, 
such as autoimmune diseases. Pneumonia presumed to be bacterial is treated with antibiotics. Pneumonia infected by mycoplasma can give rise to respiratory tract injury and other extrapulmonary complications. Researches towards MMP almost focus on exploring the physiological and biochemical characteristics of patients and treatment experience of MPP ${ }^{[1,8-9]}$. Studies on the treatment by Chinese herbs, treatment mechanism and animal model of MP infection are less reported.

QT formula containing 9 kinds of herbal medicines is a TCM compound developed by pediatrics of Shanghai Longhua hospital used for MPP treatment ${ }^{[3]}$. We previously reported that QT can effectively assist MPP children in the restoration of health, and the cure rate was $94.67 \%$ which is much higher than AZM treatment ${ }^{[3]}$. In the present study, we firstly clarified the main compounds involved in QT by LC-MS. 10 compounds involved in the QT were identified by LC-MS, which is the basis for the further study. We then successfully established the mouse model of MP infection and identified the curative effect of QT.

We established the mouse model of MPP by nasal intubation drip, and AZM and QT were employed to study the curative effect. From the results of histological examination, symptom of pneumonia the model group was the most serious, and AZM and QT effectively reduced the pulmonary interstitial inflammation. QT played better role in inflammation reduction than AM, and combination of QT and AZM provided the best. In the MP-DNA detection, QT and AT contributed equally to MP-DNA reduction, while QT + AZM showed the better effect than either of them.

PMNs and monocytes in serum directly implies the degree of inflammation symptoms and promote vascular inflammation and atherosclerosis ${ }^{[8]}$. In our study, compared with the control group, MP infection caused a marked increase of PMNs and monocytes in BALF of model group. QT can significantly reduce PMNs and monocytes in BALF.

$\mathrm{IL}-1 \beta$ is a predominant cytokine and an important mediator in pulmonary inflammation and bacterial pneumonia ${ }^{[10]}$. IL- 6 and IL-13 act as proinfammatory cytokines in human lung inflammation ${ }^{[11-13]}$. Our findings showed that QT reduces IL-1 $1 \beta$, IL- 6 and IL-13 in MP induced mice. IL-10 appears to be valuable for attenuating inflammatory damage to human lung ${ }^{[14-15]}$. IL-10 play important role in inhibiting the release of proinfammatory cytokines ${ }^{[16]}$. Thomas et al. demonstrated that IL-10 is an endogenous regulator of chemokine expression in acute lung inflammation ${ }^{[15]}$. Loebbermann et al. reported that IL-10 inhibited disease and inflammation in mice infected with RSV, especially during recovery from infection ${ }^{[16]}$. We chose to focus on IL-10 as a representative of cytokine in this class. In the present study, QT effectively increased the IL-10 level in BALF of MP-induced mice, which indicated that QT show attenuated effect in lung inflammation.

Toll-like receptors (TLRs) are known to recognize pathogen-associated molecular patterns and damageassociated molecular patterns that initiate intracellular cell signaling that subsequently activates an inflammatory response and recruits inflammatory cells ${ }^{[17]}$. Furthermore the TLR4-NF-KB pathway has been exploited as a target to prevent inflammation and carcinogenesis, and TLR4 signaling also induces COX-2 expression ${ }^{[18-20]}$. COX, officially known as prostaglandin-endoperoxide synthase (PTGS), is an 
enzyme that is responsible for formation of prostanoids which promote inflammation. From our study, TLR4, NF-KB and COX-2 expressions in MP-induced mice lung tissue were significantly down regulated by QT treatment.

Altogether, QT can effectively reduce the inflammatory response by down regulating the PMNS and monocytes in BALF, mediating inflammatory cytokines and blocking the TLR4-NF-KB-COX-2 signaling, which showed serviceable effect in MPP treatment.

\section{Conclusions}

All in all,our results indicate that QT showed favorable effect in MPP treatment by diminishing the inflammation symptoms and regulating the TLR4-NF-KB-COX-2 signaling, which could act as a new agent for MPP therapy.

\section{Abbreviations}

QT

Qingfei Tongluo formular

MP

Mycoplasma pneumoniae

MPP

Mycoplasma pneumoniae pneumonia

LC-MS

liquid Chromatograph Mass Spectrometer

AZM

azithromycin

PMNs

Polymorphonuclear neutrophils

BALF

bronchoalveolar lavage fluid

TCM

traditional Chinese medicine

TLRs

Toll-like receptors

PTGS

prostaglandin-endoperoxide synthase

\section{Declarations}

Availability of data and materials 
The datasets used in this study are available from the corresponding author upon reasonable request.

\section{Ethics approval and consent to participate}

All experimental protocols and animal handling procedures were approved by the independent Ethics Committee, Shanghai University of traditional Chinese medicine.

\section{Consent for publication}

Not applicable.

\section{Competing interests}

The authors declare that there is no conflict of interest regarding the publication of this paper.

\section{Funding}

This research is funded by National Natural Science Foundation of China Project (No. 81202722)

\section{Contributions}

$\mathrm{YJ}$ in charge of experimental design, animal experiment, analysis and interpretation of data and writing of the manuscript; ZX in charge of study supervision, revision of the manuscript; $Z \mathrm{~J}$ in charge of conception and design, revision of the manuscript; $X Z$ in charge of animal experiment, acquisition of data, analysis of data; QL and JL in charge of specimen detection, check of the manuscript and grammar and spelling. All authors read and approved the final manuscript.

\section{Acknowledgements}

Not applicable.

\section{References}

1. Shangguan Z, Sun Q, Zhang M, Ding J, Yi L, Gao Y, Zhan A, Zhao R, Ci X. Mycoplasma pneumoniae infection in hospitalized adult patients with community-acquired pneumonia in China. Journal of infection in developing countries. 2014;8:1259-66.

2. Balish MF. Mycoplasma pneumoniae, an underutilized model for bacterial cell biology. J Bacteriol. 2014;196:3675-82.

3. Jiang YH, Yu JE, Jiang ZY., Experimental study on qingfei tongluo decoction in the treatment of Mycoplasma Pneumonia mice. China Journal of Chinese Medicine. 29, 487-489. 
4. Tran $\mathrm{H}$, Allworth A, Bennett C. A case of Mycoplasma pneumoniae-associated encephalomyelitis in a 16-year-old female presenting to an adult teaching hospital. Clinical medicine insights Case reports. 2013;6:209-11.

5. Majhi A, Kundu K, Adhikary R, Banerjee M, Mahanti S, Basu A, Bishayi B. 2014. Combination therapy with ampicillin and azithromycin in an experimental pneumococcal pneumonia is bactericidal and effective in down regulating inflammation in mice. Journal of inflammation 11, 5.

6. Brown SM, Jones JP, Aronsky D, Jones BE, Lanspa MJ, Dean NC. Relationships among initial hospital triage, disease progression and mortality in community-acquired pneumonia. Respirology. 2012;17:1207-13.

7. Zasowski E, Butterfield JM, McNutt LA, Cohen J, Cosler L, Pai MP, Gottwald J, Chen WZ, Lodise TP. Relationship between time to clinical response and outcomes among Pneumonia Outcomes Research Team (PORT) risk class III and IV hospitalized patients with community-acquired pneumonia who received ceftriaxone and azithromycin. Antimicrob Agents Chemother. 2014;58:3804-13.

8. Guo L, Liu F, Lu MP, Zheng Q, Chen ZM. 2014. Increased T cell activation in BALF from children with Mycoplasma pneumoniae pneumonia. Pediatric pulmonology.

9. Meyer Sauteur PM, Bleisch B, Voit A, Maurer FP, Relly C, Berger C, Nadal D, Bloemberg GV. Survey of macrolide-resistant Mycoplasma pneumoniae in children with community-acquired pneumonia in Switzerland. Swiss Med Wkly. 2014;144:w14041.

10. Castro P, Legora-Machado A, Cardilo-Reis L, Valenca S, Porto LC, Walker C, Zuany-Amorim C, Koatz VL. Inhibition of interleukin-1 beta reduces mouse lung inflammation induced by exposure to cigarette smoke. Eur J Pharmacol. 2004;498:279-86.

11. Bhargava R, Janssen W, Altmann C, Andres-Hernando A, Okamura K, Vandivier RW, Ahuja N, Faubel S. Intratracheal IL-6 protects against lung inflammation in direct, but not indirect, causes of acute lung injury in mice. PloS one. 2013;8:e61405.

12. Ford JG, Rennick D, Donaldson DD, Venkayya R, McArthur C, Hansell E, Kurup VP, Warnock M, Grunig G. II-13 and IFN-gamma: interactions in lung inflammation. Journal of immunology. 2001;167:176977.

13. Meng ZH, Dyer K, Billiar TR, Tweardy DJ. Distinct effects of systemic infusion of G-CSF vs. IL-6 on lung and liver inflammation and injury in hemorrhagic shock. Shock. 2000;14:41-8.

14. Saadane A, Soltys J, Berger M. Role of IL-10 deficiency in excessive nuclear factor-kappaB activation and lung inflammation in cystic fibrosis transmembrane conductance regulator knockout mice. $\mathrm{J}$ Allergy Clin Immunol. 2005;115:405-11.

15. Shanley TP, Vasi N, Denenberg A. Regulation of chemokine expression by IL-10 in lung inflammation. Cytokine. 2000;12:1054-64.

16. Loebbermann J, Schnoeller C, Thornton H, Durant L, Sweeney NP, Schuijs M, O'Garra A, Johansson C, Openshaw PJ. IL-10 regulates viral lung immunopathology during acute respiratory syncytial virus infection in mice. PloS one. 2012;7:e32371. 
17. Arpaia N, Godec J, Lau L, Sivick KE, McLaughlin LM, Jones MB, Dracheva T, Peterson SN, Monack DM, Barton GM. TLR signaling is required for Salmonella typhimurium virulence. Cell. 2011;144:67588.

18. Liu L, Li YH, Niu YB, Sun Y, Guo ZJ, Li Q, Li C, Feng J, Cao SS, Mei QB. An apple oligogalactan prevents against inflammation and carcinogenesis by targeting LPS/TLR4/NF-kappaB pathway in a mouse model of colitis-associated colon cancer. Carcinogenesis. 2010;31:1822-32.

19. Ulivi V, Giannoni P, Gentili C, Cancedda R, Descalzi F. p38/NF-kB-dependent expression of COX-2 during differentiation and inflammatory response of chondrocytes. Journal of cellular biochemistry. 2008;104:1393-406.

20. Wang J, Liu YT, Xiao L, Zhu L, Wang Q, Yan T. Anti-inflammatory effects of apigenin in lipopolysaccharide-induced inflammatory in acute lung injury by suppressing COX-2 and NF-kB pathway. Inflammation. 2014;37:2085-90.

\section{Rights And Permissions}

Open Access This article is licensed under a Creative Commons Attribution 4.0 International License, which permits use, sharing, adaptation, distribution and reproduction in any medium or format, as long as you give appropriate credit to the original author(s) and the source, provide a link to the Creative Commons licence, and indicate if changes were made. The images or other third party material in this article are included in the article's Creative Commons licence, unless indicated otherwise in a credit line to the material. If material is not included in the article's Creative Commons licence and your intended use is not permitted by statutory regulation or exceeds the permitted use, you will need to obtain permission directly from the copyright holder. To view a copy of this licence, visithttp://creativecommons.org/licenses/by/4.0/. The Creative Commons Public Domain Dedication waiver (http://creativecommons.org/publicdomain/zero/1.0/) applies to the data made available in this article, unless otherwise stated in a credit line to the data.

Reprints and Permissions

\section{Figures}



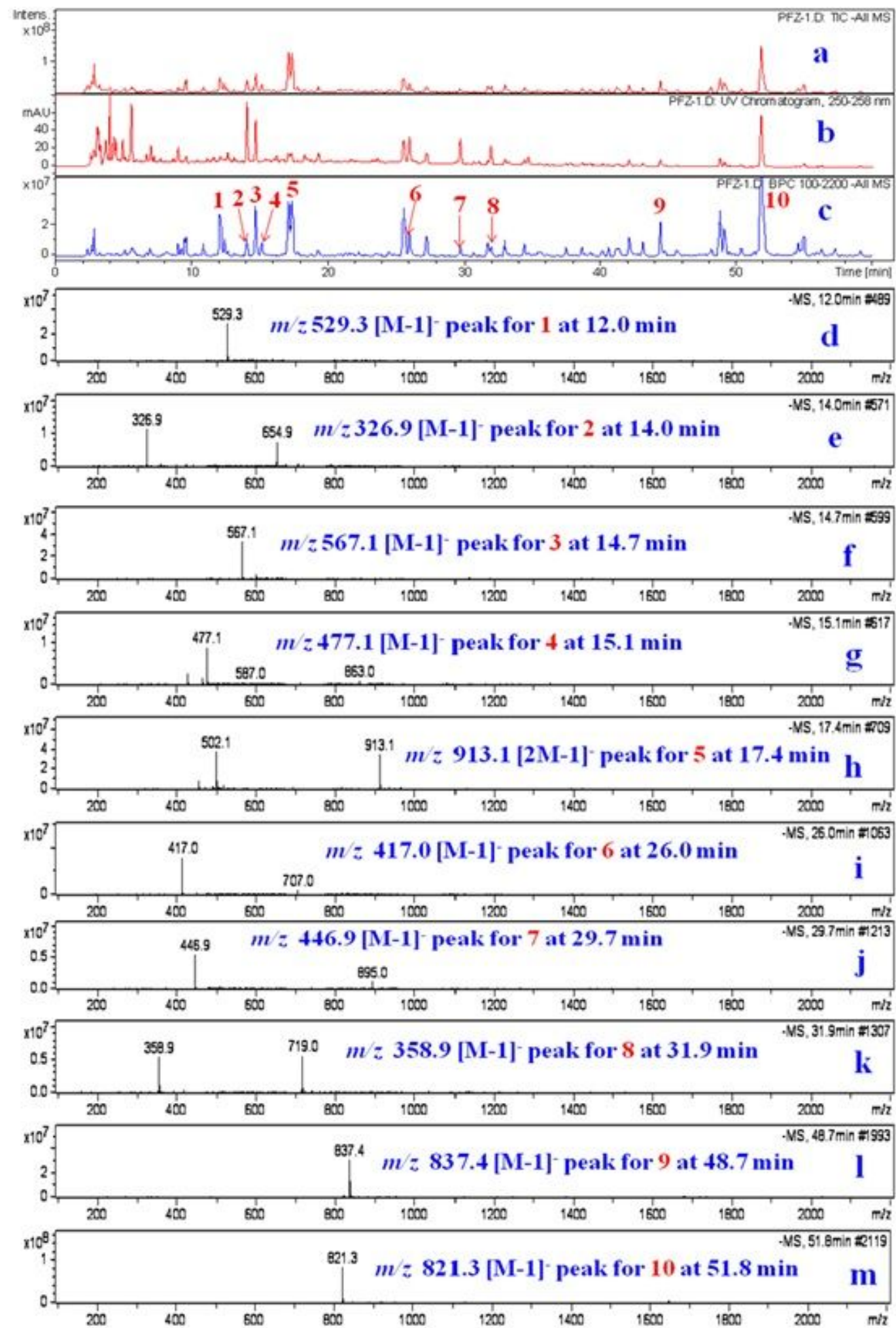

Figure 1

HPLC/ESI-MS chromatogram of the QT aqueous extract in negative mode (a: total ion chromatogram b: UV chromatogram c: base peak chromatogram d: ESI-MS spectra of [M-1]- ion of compound 1 (retention time: $12.0 \mathrm{~min}$ ) e: ESI-MS spectra of [M-1]- ion of compound 2 (retention time: $14.0 \mathrm{~min}$ ) f: ESI-MS spectra of [M-1]- ion of compound 3 (retention time: $14.7 \mathrm{~min}$ ) g: ESI-MS spectra of [M-1]- ion of compound 4 (retention time: $15.1 \mathrm{~min}$ ) h: ESI-MS spectra of [M+Cl]- and [2M-1]- ion of compound 5 (retention time: 
$17.4 \mathrm{~min}$ ). i: ESI-MS spectra of [M-1]- ion of compound 6 (retention time: $26.0 \mathrm{~min}$ ). j: ESI-MS spectra of [M-1]- ion of compound 7 (retention time: $29.7 \mathrm{~min}$ ). $\mathrm{k}$ : ESI-MS spectra of [M-1]- ion of compound 8 (retention time: $31.9 \mathrm{~min}$ ). I: ESI-MS spectra of [M-1]- ion of compound 9 (retention time: $48.7 \mathrm{~min}$ ). $\mathrm{m}$ : ESI-MS spectra of [M-1]- ion of compound 10 (retention time: $51.8 \mathrm{~min}$ ).

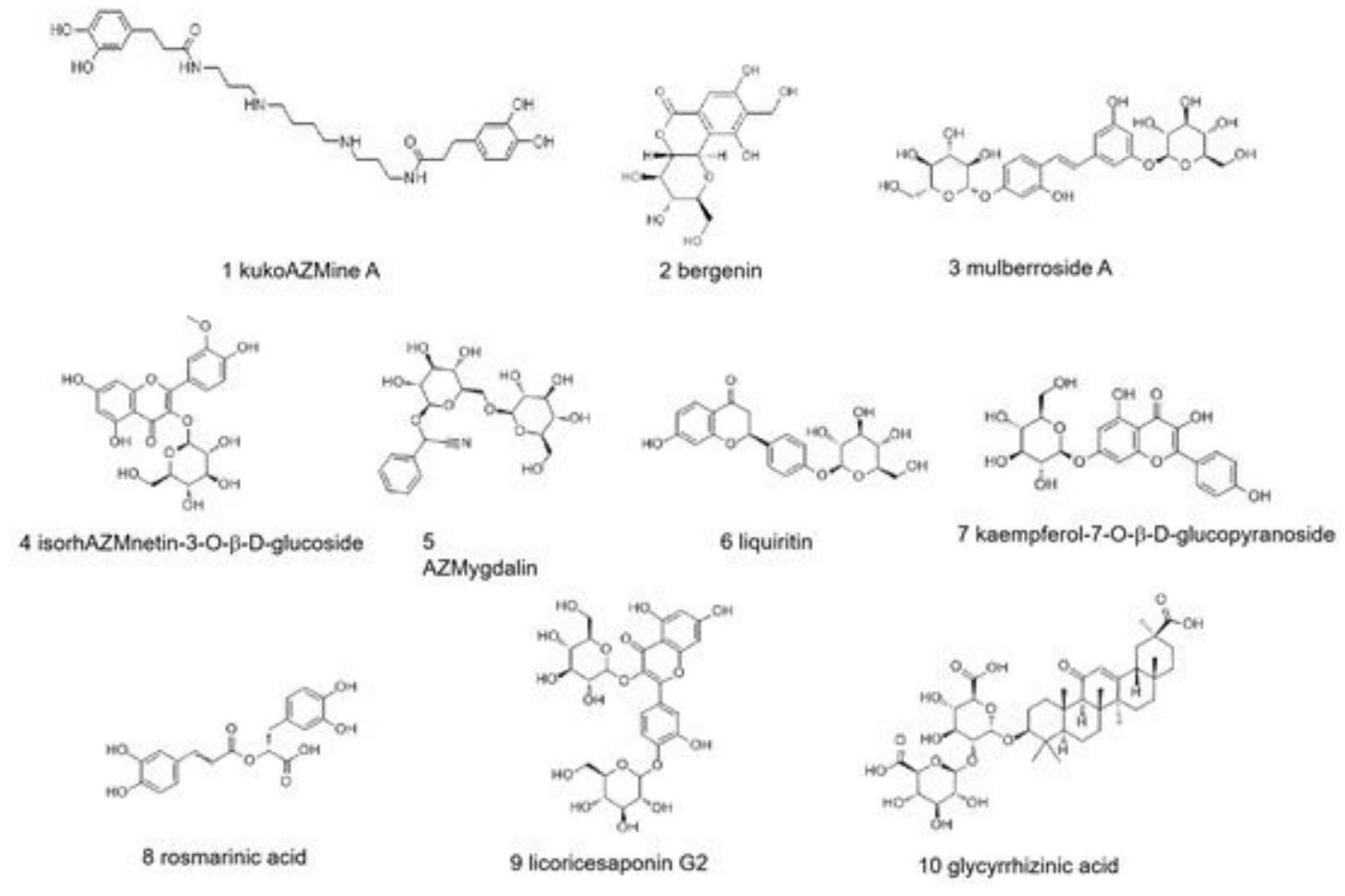

Figure 2

Chemical structures of compounds identified in QT. 3.2 Estimation of inflammatory cells in BALF
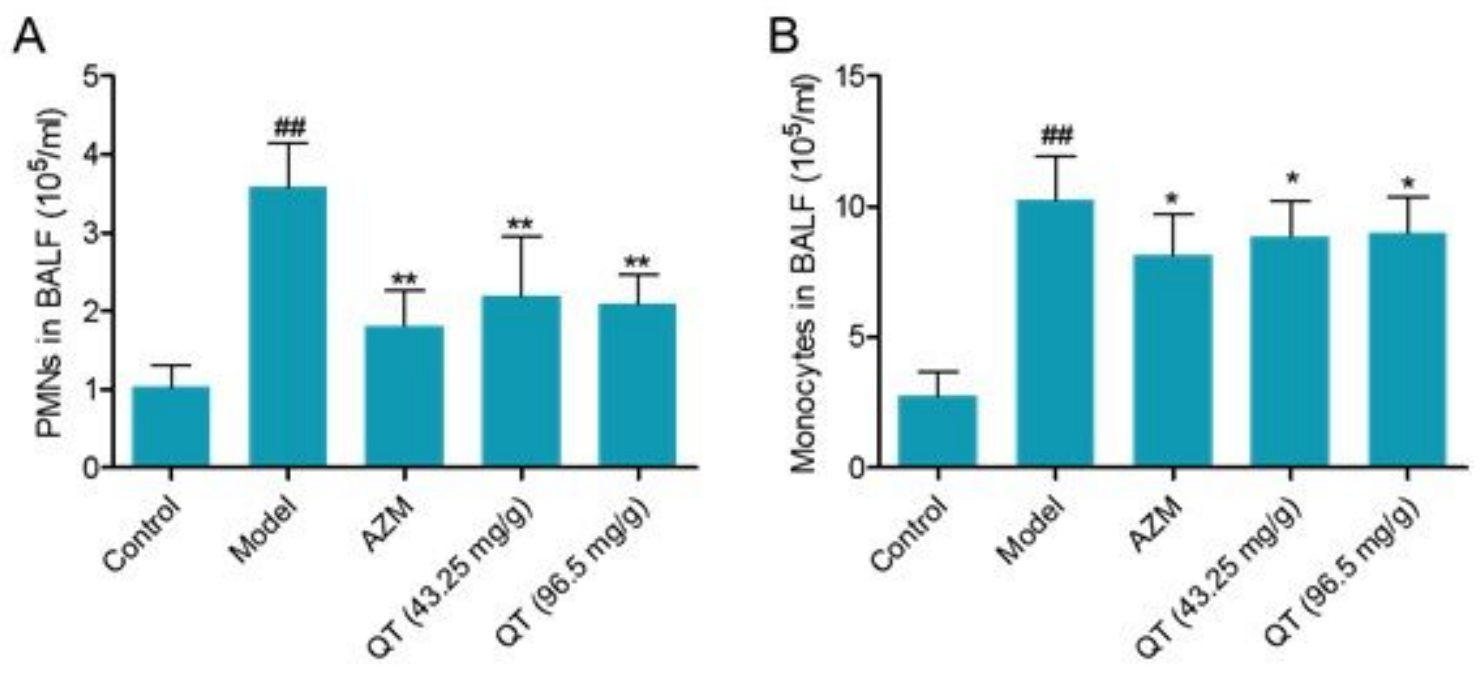

Figure 3

PMNs and monocytes in BALF. After AM and QT treatment for 3 days, PMNs (A) and monocytes (B) in $B A L F$ were counted. Data was presented as mean $\pm S D$, compared with the control group, \#\#P<0.01; compared with the model group, ${ }^{*} \mathrm{P}<0.01 ; \mathrm{n}=10$. 

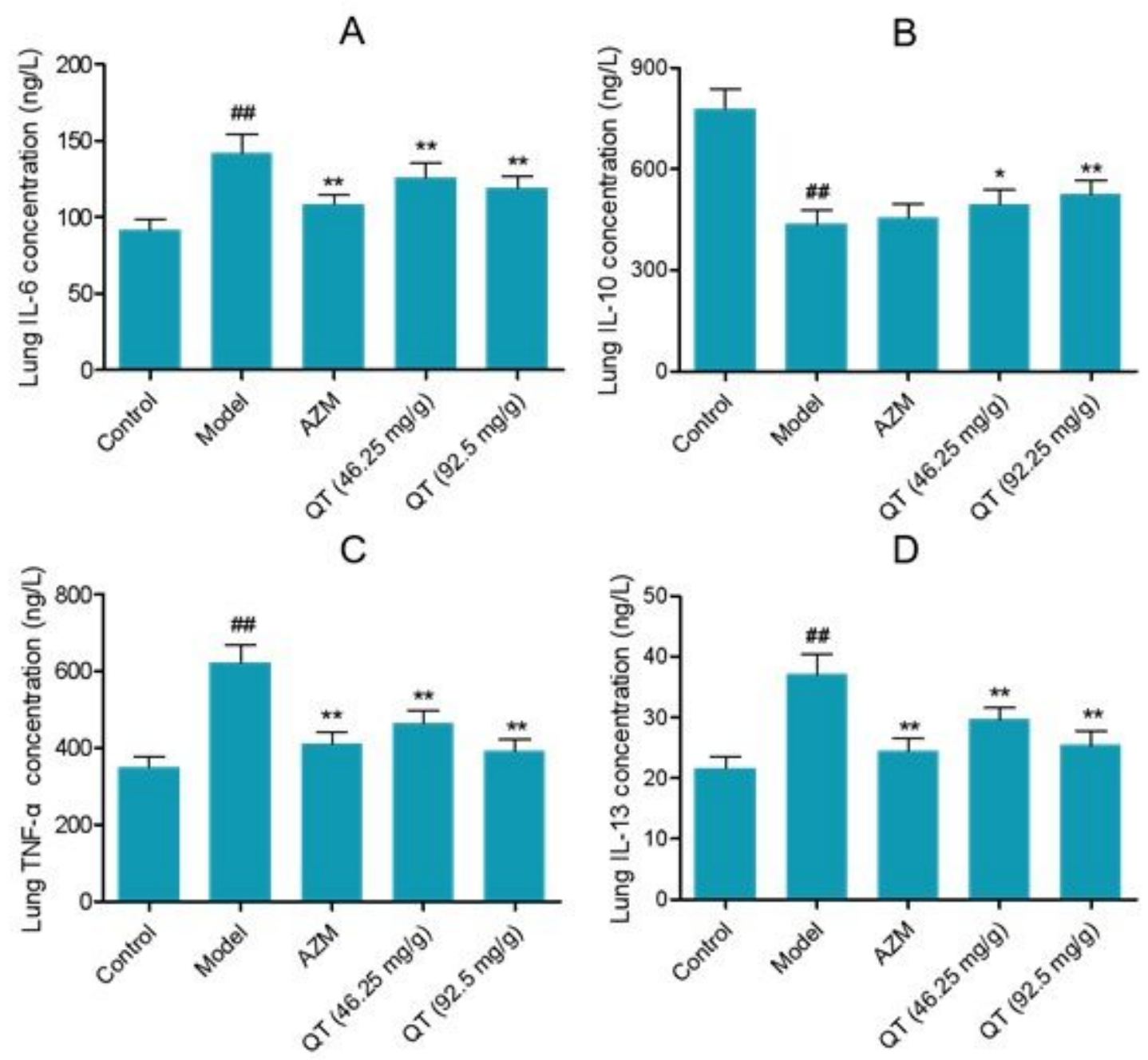

\section{Figure 4}

Effect of QT on cytokines in BALF. MP induced mice were treated with AZM and QT $(43.25 \mathrm{mg} / \mathrm{g}$ and 96.5 $\mathrm{mg} / \mathrm{g}$ ) for 3 days, levels of IL-6 (A), IL-10(B), TNF-a (C) and IF-13 (D) were determined by ELISA. Data was presented as mean $\pm \mathrm{SD}$, compared with the control group, \#\#P<0.01; compared with the model group, $\star * \mathrm{P}<0.01 ; \mathrm{n}=10$.
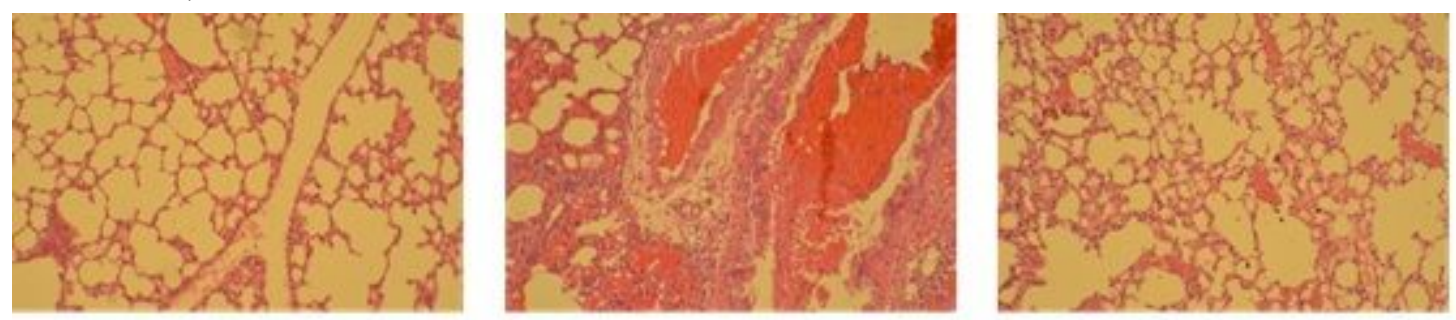
A. Control
B.. Model
D. AZM

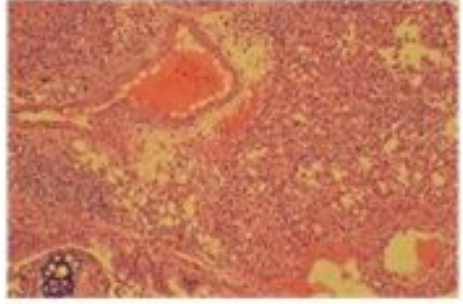

E. QT $(43.25 \mathrm{mg} / \mathrm{g})$

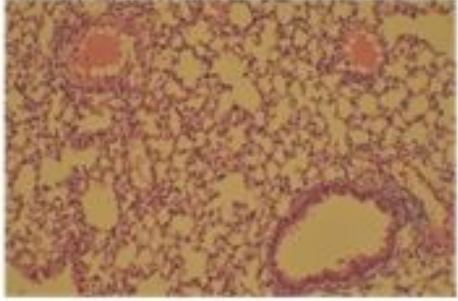

F. QT (96.5 mg/g) 
Figure 5

Pathological changes in lungs of BALB/c mice. Inferior lobe of right lung isolated was fixed with $4 \%$ paraformaldehyde, embedded with paraffin and cut into slices for HE staining. Morphometric analysis was performed by optical microscope.
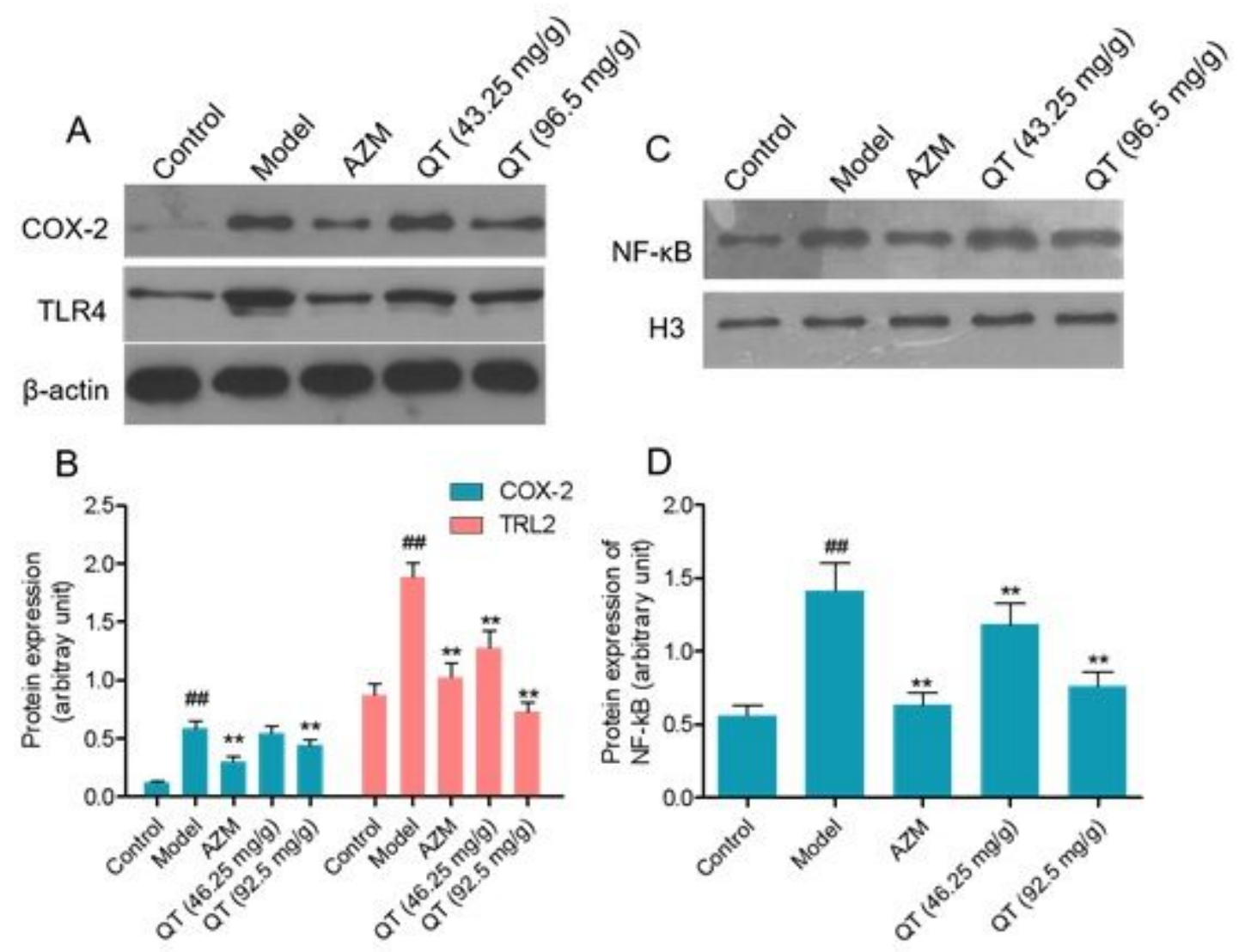

\section{Figure 6}

Effects of QT on COX-2, TLR4, TLR4 and NF-KB expression. (A, B and C) MP induced mice were treated with AZM and QT $(43.25 \mathrm{mg} / \mathrm{g}$ and $96.5 \mathrm{mg} / \mathrm{g}$ ) for 3 days, COX-2, TLR2 and TLR4 expression were measured by western blot. ( $D$ and $E$ ) NF-KB expression was also identified. Data was presented as mean $\pm S D$, compared with the control group, \#\#P<0.01; compared with the model group, $* * P<0.01 ; n=10$. 